\title{
The Integration, Perceptions, and Implementation of Legislative Advocacy Within U.S Colleges and Schools of Pharmacy
}

\author{
E. Michael Murphy, PharmD, Natalie Hagy, Julia Miller, Jennifer L. Rodis, PharmD \\ The Ohio State University, College of Pharmacy, Columbus, Ohio \\ Corresponding Author: Jennifer L. Rodis, The Ohio State University, College of Pharmacy, 500 W. 12th Ave., Columbus, OH \\ 43210. Tel: 614-247-8391. Email: rodis.2@osu.edu
}

Submitted March 29, 2021; accepted September 8, 2021; ePublished September 2021

Objective. To assess: 1) current practices of colleges and schools of pharmacy pertaining to teaching legislative advocacy, 2) engagement of staff, faculty, postgraduates, students, and administrators at colleges and schools of pharmacy in legislative advocacy partnerships and activities, and 3) future goals for legislative advocacy involvement by academic pharmacy institutions.

Methods. An electronic survey was distributed to Deans of colleges and schools of pharmacy across the U.S. via a list of emails from the American Association of Colleges of Pharmacy. Respondents completed 53 questions to identify involvement, barriers, and relative importance related to legislative advocacy. Responses were evaluated using descriptive statistics.

Results. The survey accrued responses from 48 of 143 (33\%) colleges and schools of pharmacy. Of the respondents, 16\% required a course on advocacy and approximately $50 \%$ offered an advocacy elective. A majority of institutions highly ranked ( $\geq 7$ on a scale of 1-10) their institution's involvement and importance of legislative advocacy in external collaboration (involvement: 58.8\%; importance: $75.8 \%$ ). A majority of institutions highly ranked the importance of faculty, staff, and postgraduate roles in advocacy (60\%); however, involvement was not ranked as strongly (42.3\%). Fifty percent of institutions plan to expand involvement in legislative advocacy.

Conclusion. Colleges and schools of pharmacy in the U.S. highly ranked the importance of legislative advocacy; many feel their involvement is strong with plans to expand. Moving forward, curricula and resource allocation should be reviewed to diminish the dissonance between importance and implementation of legislative advocacy components. Keywords: legislative advocacy, pharmacy education, postgraduate training, healthcare, policy

\section{INTRODUCTION}

Pharmacists are required to learn laws that govern practice and stay updated on evidence that influences the delivery of high-quality patient care. However, professional engagement is variable when it comes to legislative advocacy, which influences changes in laws and regulations that shift and advance pharmacy practice. The Joint Commission of Pharmacy Practitioners (JCPP) Vision Statement states that "Pharmacists will be accountable for health, medication-related, and patient and population-specific needs." Unfortunately, laws governing pharmacist scope of practice and reimbursement for services present barriers to reaching this vision. Policy change is necessary in order to achieve JCPP's vision as well as address the multifaceted social issues that affect patient health and access to care. ${ }^{2}$ A way to influence policy change is through legislative advocacy, which is defined along with other terms in Table I. Research has shown that citizens, professionals, and organizations can influence congressional decisions, indicating that advocacy can be a key component in changing legislation. ${ }^{3}$ Legislative change is essential to advance patient care; accordingly, skill development in legislative advocacy may need to be included in Doctor of Pharmacy (PharmD) training.

According to the Center for the Advancement of Pharmacy Education (CAPE) that guides accreditation of PharmD programs, pharmacists should be trained as educators. CAPE states that being an educator "involves conducting a learning needs assessment of constituents who would benefit from pharmacist delivered education (e.g.

patients/caregivers, technicians, pharmacy students, fellow pharmacists, other health care providers, and legislators)". ${ }^{4}$ To align with the CAPE guidelines, assessing the educational needs of legislators on current issues in pharmacy should be included within PharmD training. Despite this expectation around legislative advocacy in pharmacy education, no reports or literature exist that describe the integration of legislative advocacy in colleges and schools of pharmacy in the United States (U.S.).

Few studies, including one conducted by Blake and Powell from the University of South Carolina, Columbia, have evaluated individual components of advocacy teaching and learning activities such as an elective. ${ }^{5}$ This, and similar 
articles, show that implementation of advocacy into the PharmD curriculum increases competence and confidence in participating in legislative advocacy. ${ }^{6}$ Still, there is a gap in the literature related to how colleges and schools of pharmacy across the country integrate legislative advocacy teaching and learning activities through required courses, electives, experiential curriculum, and co-curricular opportunities. Additionally, literature does not currently address partnerships with stakeholders such as state boards of pharmacy and professional organizations that influence policy change. By evaluating legislative advocacy activities of colleges and schools of pharmacy across the country via an electronic survey to institution leadership, the roles academic institutions play in the practice and teaching of legislative advocacy can be quantified and goals for the future of pharmacy advocacy can be informed. The objectives of this project were to assess the current practices of colleges and schools of pharmacy pertaining to teaching legislative advocacy, the engagement of staff, faculty, fellows, residents, and administrators at the colleges and schools of pharmacy in legislative advocacy activities, and consider future goals for legislative advocacy in academic pharmacy institutions.

\section{METHODS}

An electronic survey was distributed via email through Qualtrics ${ }^{\mathrm{TM}}$ to 143 Deans of colleges and schools of pharmacy across the U.S. The survey could be completed by staff, faculty, fellows, residents, and/or administrators, as delegated by the Dean. This survey was developed by two student pharmacists, a postgraduate fellow, and a senior faculty member and Associate Dean with experience in advocacy within the scope of pharmacy academia. Prior to distribution, the survey was pilot tested with pharmacy educators and the Associate Dean for Academic Affairs. The fifty-threequestion survey included multiple choice, open-ended, and scale of one to ten questions, evaluating colleges and schools of pharmacy on stated objectives. Respondents were not required to answer every question. The survey was broken up into six domains: 1) didactic curriculum, 2) experiential curriculum, 3) co-curriculum, 4) faculty, staff, and postgraduate roles, 5) external collaborations, and 6) overall institutional engagement. Within each domain, questions assessed activities of institutions along with a self-assessment on a ten-point scale of their institution's perceived level of involvement and importance. Researchers used the following scale to describe a response as being a high ranking: involvement: $\geq 7$ out of a scale of 1-10, with one being not well and 10 being extremely well; importance $\geq 7$ out of a scale of 1-10, with one being not important and 10 being extremely important. The study was not designed to evaluate any association or compare between rankings of involvement and importance. Demographics were gathered from respondents, highlighting number of public and private institutions, number of institutions established before and after the year 2000, if a recent curriculum restructuring had occurred, how many colleges/schools and/or satellite campuses existed in their state, location in relation to state capital, and census region of the U.S.

Email addresses for colleges and schools of pharmacy were obtained through the American Association of Colleges of Pharmacy (AACP) Deans email list. Survey data was collected through the use of Qualtrics ${ }^{\mathrm{TM}}$ online survey software with all identifiable information being stored on the Qualtrics ${ }^{\mathrm{TM}}$ online survey software secure online database. The survey was distributed on August 1, 2020 and then two email reminders were sent on September 1, 2020 to signal four weeks left of the survey and September 15, 2020 for two weeks left to complete the survey. The survey closed on September 30, 2020.

Consent was attained by selecting the option to complete the survey and all survey responses were de-identified for aggregate analysis. Participants were eligible to be entered in a drawing to receive a $\$ 100$ Amazon gift card at the conclusion of the survey. Ethical approval to conduct the study was obtained from the Institutional Review Board of The Ohio State University.

\section{RESULTS}

Forty-eight of 143 (33.6\%) colleges and schools of pharmacy responded to the survey. Demographic information for the responding institutions is included in Table II. A majority of responding institutions had between two and seven colleges or schools of pharmacy in their state and there was an equal split of institutions geographically located near their state capital (within an hour drive) and those located further away from their state capital.

Results related to institutional involvement and perceived importance of these six domains are included in Table III. A majority of institutions highly ranked ( $\geq 7$ out of a scale of 10) their institution's involvement and importance for the integration of advocacy into the following domains: didactic curriculum (involvement: 58.5\%; importance: 63.9\%), co-curriculum (involvement: 90.9\%; importance: 90.5\%), external collaboration (involvement: 58.8\%; importance: 75.8\%), and overall institutional engagement (involvement: $66.7 \%$; importance: $75.9 \%$ ). A majority of respondents highly ranked ( $\geq 7$ out of a scale of 10) their institutions perceived importance of integration of legislative advocacy into the experiential curriculum (importance: 51.4\%) and faculty, staff, and postgraduate roles (importance: 60\%); however, involvement was not ranked as highly in these categories (involvement $40 \%$ and involvement $42.3 \%$, respectively). Results of questions within the six domains of the survey are summarized below. 
In the didactic curriculum, an overwhelming majority of respondents $(82.9 \%)$ do not require a course with a focus in legislative advocacy in their PharmD programs, however, a comparable majority (85.4\%) have legislative advocacy topics embedded in required courses in their curricula. For students with an interest in legislative advocacy, many colleges and schools of pharmacy (40\%) offer an elective, with these electives most frequently being offered on an annual basis (76.5\%) generally enrolling between 5-25 students (70.6\%).

Experiential curriculum with a focus on legislative advocacy is more prominent during Advanced Pharmacy Practice Experiences (APPEs) with 63.4 percent of colleges and schools of pharmacy offering at least one APPE rotation as opposed to only five percent of colleges and schools of pharmacy offering at least one Introductory Pharmacy Practice Experiences (IPPEs) with a focus on legislative advocacy. A majority (80.8\%) of IPPE and APPE rotations with a focus on legislative advocacy are offered in partnership with state or national pharmacy associations.

There are diverse co-curricular experiences offered that focus on legislative advocacy with a majority of institutions reporting between one to five co-curricular experiences per year (85.7\%). The most commonly reported experiences include legislative advocacy workshops $(n=31)$, panel sessions involving individuals connected to legislative advocacy $(n=31)$, legislator visits to campus $(n=28)$, and legislator visits with students, the institution, or at pharmacy events $(n=22)$. Experiences highly available to institutions included statewide pharmacy and/or student pharmacist legislative advocacy days. 92.9 percent of institutions reported their states hold pharmacist legislative advocacy days at least annually and 86.4 percent of institutions reported their states hold student pharmacist legislative advocacy days.

Many institutions employ individuals focused in legislative advocacy. The most commonly reported category include faculty members $(n=33)$ and administrators $(n=28)$. These individuals participate in a variety of experiences that support legislative advocacy efforts at their colleges or schools of pharmacy; the most frequently reported include coordinating students to visit the State House/Capitol Building/legislator office $(n=32)$ and legislative advocacy events $(n=27)$. Specific to legislative days, 23 institutions reported that their faculty and students participated.

Postgraduate involvement in legislative advocacy is limited. Of all role designations (staff, faculty, postgraduate, administrator, or other) that could be involved in legislative advocacy, only 5.5 percent of responses indicated postgraduate involvement. Overall, within post-graduate programs, 10.9 percent of residencies, five percent of fellowships, and two percent of research $(\mathrm{PhD}, \mathrm{MS})$ programs report trainees have some effort in advocacy. However, only one percent of residencies and two percent of fellowships report trainees have significant involvement in advocacy. When evaluating programs individually, residencies have the greatest reported percentage involvement in any amount of advocacy efforts with 44.4 percent of residency programs reporting in comparison to 26.9 percent of fellowship programs, 8.3 percent of research (Doctor of Philosophy (PhD), Master of Science (MS)) programs, and zero percent of postdoctoral researcher programs.

There are a variety of external collaborators that colleges or schools of pharmacy partner with on legislative advocacy efforts. A majority of institutions report either a strong or very strong (out of a 5-point Likert scale from very weak to very strong) level of collaboration including 97.5 percent with state pharmacy associations, 82.1 percent with national pharmacy associations, 80.6 percent with other colleges or schools of pharmacy in the state, 77.5 percent with state boards of pharmacy, and 69.7 percent with local pharmacy associations.

A majority (64.1\%) of institutions report that legislative advocacy is included in their college or school of pharmacy's strategic plan. Although there is perceived importance of legislative advocacy in colleges or schools of pharmacy, numerous barriers remain. The most common barriers include 31.3 percent of institutions reporting lack of dedicated resources and 20.3 percent of institutions reporting lack of faculty or staff interest. In addition, 14.1 percent institutions reported restrictions with university policy. The survey did not inquire of the type of policy restrictions, but open-ended comments and author experience suggest limitations including public universities having restrictions on government relations, and restrictions from institutional government affairs offices to engage on issues that may be in contradiction to other stakeholders in the institution.

In addition to receiving information from institutions regarding current efforts in legislative advocacy, institutions had the opportunity to share future plans to promote legislative advocacy in their institution's curriculum, co-curriculum, experiential curriculum, or partnerships and provide any additional comments regarding the role colleges or schools of pharmacy should play in legislative advocacy. Regarding future plans in legislative advocacy, a near even split of institutions plan to continue current efforts $(47.6 \%)$ or plan to do more $(52.4 \%)$, with no respondents indicating decreasing efforts. Within the responses of those that plan to do more in the future, the most common goal (40\%) was expanding or enhancing partnerships with external partners that prioritize legislative advocacy. Following this, institutions plan to increase student legislative day participation (20\%) and enhance legislative advocacy involvement in experiential curriculum (20\%). A majority of institutions (70\%) expressed that colleges and schools of pharmacy should be primarily involved with legislative advocacy. 


\section{DISCUSSION}

This study aimed to illustrate the current landscape of legislative advocacy curricula and involvement at colleges and schools of pharmacy. The results of this study indicate the current practices, institutional self-assessments, and perceived importance of legislative advocacy. Additionally, potential areas of growth for legislative advocacy in didactic, experiential curriculum, and co-curricular experiences, along with involvement of faculty, staff, postgraduates, and external partners were identified. It is important to note that when discussing the results of this study, authors are referring to the respondents of each individual question as respondents were not required to answer every question. Participants of this study come from a spectrum of colleges and schools of pharmacy across the country representing $20 \%$ of private institutions and about $31 \%$ of public institutions. The results of this study can help to understand how colleges and schools perceive they are currently performing in legislative advocacy areas, how important legislative advocacy is to institutions, and perceptions from colleges and schools on strategies to improve involvement in legislative advocacy.

On rating institutional involvement within each of these domains, a majority reported high rankings ( $\geq 7$ out of a scale of 10) in all domains, except for integration of legislative advocacy into the experiential curriculum and in faculty, staff, and postgraduate roles. When evaluating the importance of advocacy, a majority of institutions reported high rankings ( $\geq 7$ out of a scale of 10) in all six domains. Co-curriculum ranked highest in involvement in legislative advocacy and institutional ranked importance. Overall, it appears a majority of colleges and schools of pharmacy would assess their current involvement in legislative advocacy in the didactic curriculum, co-curriculum, external collaboration, and overall engagement positively and rank all six domains as important. Only two domains, experiential curriculum and faculty, staff, and postgraduates' roles, demonstrated a moderate ranking in respondents' involvement that did not align with the high ranking of importance. This identifies a gap in which institutions identified legislative advocacy in the experiential curriculum and in faculty, staff, and postgraduate roles as important; however, their institutions did not describe performing in these areas at a high level. This is an opportunity for growth.

All respondents reported that their institutions planned to either continue or increase current involvement in legislative advocacy. This may mean continued growth of advocacy efforts across the six domains, highlighting the future, larger roles that academic institutions could play in advocacy efforts. The potential growth can also be observed by the proportion of institutions $(n=27,65.9 \%)$ donning legislative advocacy efforts in their strategic plans. One of the primary methods by which institutions hope to increase their advocacy efforts is by expanding external relationships. The expansion of external relationships could include professional pharmacy associations, state boards of pharmacy, healthcare systems or companies involved in policy change, or other community or professional organizations. Many of the planned expansions in the future align with institutions' lowest ranked domain in the self-assessment portion of the survey: integration of advocacy in experiential curriculum.

Despite interest in further participation in legislative advocacy, several barriers were identified that may limit involvement. Primary barriers include lack of resources and staff/faculty interest in participation. This juxtaposition with institutional ranked importance of advocacy efforts and involvement across the six domains may be explained by these identified barriers. Notably, the number of trainees, such as residents, fellows, and graduate students, involved in legislative advocacy is low at academic pharmacy institutions. There may be an opportunity to address the resource gap by designating trainee resources while also encouraging involvement of staff and faculty. Additional barriers that exist such as university policies that prohibit involvement in legislative advocacy should be clarified to determine what activities are permitted for students and employees, including determining if acting on behalf of themselves as citizens is allowable instead of on behalf of the organization.

Limitations of the study include the number of respondents to the survey as well as unique roles of respondents at each college and school of pharmacy. Authors only received a portion of all colleges and schools of pharmacy completing the survey. The respondents of this survey represent a cross-section of U.S. pharmacy academic institutions with demographics that align with those of the academy. ${ }^{7}$ With one representative completing the survey, there is the chance that staff, faculty, administrators, and post-graduates may be participating in advocacy efforts, but this is not a part of their formal job description and these activities may not have been captured or reported when responding to the survey. Additionally, perceptions of importance of the domains were indicated by the responder and may not represent the views of all leadership at the college or school of pharmacy. As a cross-section, this study provides a useful and the largest scale to date summary and description, but does not provide a complete report of legislative advocacy within all colleges or schools of pharmacy in the U.S.

The results of the study illustrate the most comprehensive data available on legislative advocacy activities within colleges and schools of pharmacy in the U.S. Overall, respondents indicate involvement in legislative advocacy is important and should be expanded. This study forms a foundation for further research into the specific topics and strategies for teaching legislative advocacy as well as a platform to launch further development of legislative advocacy integration across the aforementioned six domains. The knowledge and skills of student pharmacists in legislative 
advocacy, the influence of the pharmacy academy on policy change to advance health care and pharmacy practice, and examination of opportunities for experiential curriculum and post-graduate training programs are areas for future investigation.

\section{CONCLUSION}

Colleges and schools of pharmacy in the U.S. overall highly ranked the importance of legislative advocacy for their academic institutions and many feel their involvement is strong, especially in the co-curriculum. Opportunities exist to showcase and enhance involvement in legislative advocacy in experiential curriculum and post-graduate training. Moving forward, curricula and resource allocation should be reviewed to diminish the dissonance between importance and implementation of legislative advocacy components.

\section{ACKNOWLEDGEMENTS}

Results have been shared as a podium presentation at the Ohio Pharmacists Association Annual Meeting in April 2021. Funding source: Internal departmental funds were used to support the participant incentive.

\section{REFERENCES}

1. Vision for Pharmacists' Practice. Joint Commission for Pharmacy Practitioners. https://jcpp.net/resourcecat/jcppvision-for-pharmacists-practice/. Accessed August 17, 2021.

2. Ojo A, Sandoval RS, Soled D, et al. No Longer An Elective Pursuit: The Importance Of Physician Advocacy In Everyday Medicine. Health Affairs Blog. https://www.healthaffairs.org/do/10.1377/hblog20200817.667867/full/. Published August 19, 2020. Accessed August 17, 2021.

3. Fitch B, Goldschmidt K, Cooper NF. Citizen-Centric Advocacy: The Untapped Power of Constituent Engagement. Congressional Management Foundation.

https://www.congressfoundation.org/projects/communicating-with-congress/citizen-centric-advocacy-2017.

Published 2017. Accessed August 17, 2021.

4. Medina MS, Plaza CM, Stowe CD, et al. Center for the Advancement of Pharmacy Education 2013 educational outcomes. Am J Pharm Educ. 2013;77(8):Article 162.Blake EW, Powell PH. A Pharmacy Political Advocacy Elective Course. Am J Pharm Educ. 2011;75(7). doi:10.5688/ajpe757137.

5. Mospan CM, Mospan GA. Assessing the impact of a didactic lecture for student pharmacists on legislative advocacy. Curr Pharm Teach Learn. 2018;10(10):1363-1374. doi:10.1016/j.cptl.2018.07.002.

6. Academic Pharmacy's Vital Statistics. American Association of Colleges of Pharmacy. https://www.aacp.org/article/academic-pharmacys-vital-statistics. Accessed August 17, 2021.

7. Deloatch KH, Gannett PM, Hagemann TM, et al. Student engagement in professional political advocacy in colleges/schools of pharmacy. Curr Pharm Teach Learn. 2012;4(3):207-211. doi:10.1016/j.cptl.2012.04.008.

8. Accreditation Council for Pharmacy Education. Accreditation Standards and Key Elements for the Professional Program in Pharmacy Leading to the Doctor of Pharmacy Degree ("Standards 2016"). Published February 2015. https://www.acpe-accredit.org/pdf/Standards2016FINAL.pdf. Accessed August 17, 2021. 
Table I. Key definitions ${ }^{8-9}$

\begin{tabular}{ll}
\hline Term & Definition \\
\hline $\begin{array}{l}\text { Legislative } \\
\text { advocacy }\end{array}$ & $\begin{array}{l}\text { [the] "influence of practitioners, pharmacy professional organizations, and regulatory bodies } \\
\text { have to effect changes in policies, regulations, or legislation that advances the profession, } \\
\text { improves health care delivery, and ultimately enhances efficacy, safety, and cost-effectiveness } \\
\text { of pharmacotherapy." }\end{array}$ \\
$\begin{array}{l}\text { Experiential } \\
\text { curriculum }\end{array}$ & $\begin{array}{l}\text { "experiences that are in-depth, structured, and comprehensive in the aggregate, and carefully } \\
\text { coordinated with other components of the PharmD curriculum." }\end{array}$ \\
& $\begin{array}{l}\text { "activities that complement and advance the learning that occurs within the formal didactic } \\
\text { and experiential curriculum. This includes activities such as service hours, student } \\
\text { professional organization opportunities, and other health care related events" }\end{array}$ \\
\hline
\end{tabular}

Table II. Demographic information of schools and colleges of pharmacy

\begin{tabular}{|c|c|}
\hline & $\begin{array}{l}\text { Response } \\
\text { n (\%) }\end{array}$ \\
\hline \multicolumn{2}{|l|}{ Type of institution } \\
\hline Public & $22(59.5)$ \\
\hline Private & $15(40.5)$ \\
\hline \multicolumn{2}{|c|}{ Curriculum revision or redesign in the last 5 years } \\
\hline Yes & $27(77.1)$ \\
\hline No & $8(22.9)$ \\
\hline \multicolumn{2}{|c|}{ Year college or school was established } \\
\hline Before 2000 & $19(54.3)$ \\
\hline After 2000 & $16(45.7)$ \\
\hline \multicolumn{2}{|c|}{ Length of PharmD program } \\
\hline 3 years & $3(8.8)$ \\
\hline 4 years & $27(79.4)$ \\
\hline 6 years & $4(11.8)$ \\
\hline \multicolumn{2}{|c|}{ Number of pharmacy schools in the state } \\
\hline$\leq 1$ & $2(5.9)$ \\
\hline $2-5$ & $15(44.1)$ \\
\hline $6-10$ & $13(38.2)$ \\
\hline $11-14$ & $4(11.8)$ \\
\hline \multicolumn{2}{|c|}{ Number of satellite campuses associated with college or school of pharmacy } \\
\hline 0 & $28(82.4)$ \\
\hline 1 & $6(17.7)$ \\
\hline \multicolumn{2}{|c|}{ College or school of pharmacy located within an hour drive to state capital } \\
\hline Yes & $16(45.7)$ \\
\hline No & $19(54.3)$ \\
\hline \multicolumn{2}{|c|}{ Number of institutional responses by census region } \\
\hline Northeast & $4(10.5)$ \\
\hline Midwest & $9(23.7)$ \\
\hline West & $10(26.3)$ \\
\hline South & $15(39.5)$ \\
\hline
\end{tabular}


Table III. Colleges or schools or pharmacy rating of institution integration and perception of importance of legislative advocacy

Standard

Mean Median Deviation Count

Integration of legislative advocacy into the didactic curriculum

Involvement $^{\mathrm{a}}$

Importance $^{\mathrm{b}}$

6.39

Integration of legislative advocacy into the experiential curriculum

Involvement $^{\mathrm{a}}$

Importance ${ }^{\mathrm{b}}$

2.27

41

$\begin{array}{llll}7.36 & 8 & 2.29 & 36\end{array}$

Integration of legislative advocacy into the co-curriculum

Involvement $^{\mathrm{a}}$

Importance ${ }^{\mathrm{b}}$

$\begin{array}{llll}5.63 & 6 & 2.27 & 40\end{array}$

$\begin{array}{llll}6.51 & 7 & 2.23 & 35\end{array}$

$\begin{array}{llll}7.68 & 8 & 1.76 & 22\end{array}$

Involvement of faculty, staff, and postgraduates in legislative advocacy Involvement $^{\mathrm{a}}$

Importance $^{\mathrm{b}}$

$\begin{array}{llll}7.68 & 8 & 1.76 & 22 \\ 8.14 & 8 & 1.53 & 21\end{array}$

Collaboration with external partners in legislative advocacy Involvement $^{\mathrm{a}}$ Importance ${ }^{\mathrm{b}}$

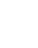

$\begin{array}{llll}5.92 & 6 & 2.04 & 26\end{array}$

$\begin{array}{llll}6.68 & 7 & 2.29 & 25\end{array}$

Overall engagement and promotion of legislative advocacy Involvement $^{\mathrm{a}}$ Importance ${ }^{\mathrm{b}}$

\begin{tabular}{llll}
6.82 & 7 & 2.37 & 34 \\
7.85 & 8 & 1.99 & 33 \\
& & & \\
7.06 & 7 & 2.08 & 33 \\
7.97 & 8 & 1.95 & 29 \\
\hline
\end{tabular}

${ }^{\mathrm{a}}$ Rated on a scale of $1-10$, with 1 being not well and 10 being extremely well

${ }^{\mathrm{b}}$ Rated on a scale of $1-10$, with 1 being not important and 10 being extremely important 